\title{
Effect of Technology-Enabled Time-of-Use Energy Pricing on Thermal Comfort and Energy Use in Mechanically-Conditioned Residential Buildings in Cooling Dominated Climates
}

\begin{abstract}
:
The effects of automatic indoor set point temperature setbacks using smart thermostats in response to time-of-use (TOU) electricity rates structures on occupant thermal comfort are evaluated for representative single family residential buildings located in 3 climate zones with dominant cooling loads. Building energy models (BEM) of single family homes are evaluated using a full factorial experimental design to create a response surface which provides a continuous function to evaluate the impact of four design variables on long-term thermal comfort indices, including Average Percent of People Dissatisfied (Average PPD), and Percentage Outside Thermal Comfort Zone (POS). These design variables include indoor set point temperature, degrees of setback temperature in cooling mode, building thermal mass, and air exchange rate for each climate zone. These are compared to the relative energy savings resulting from TOU thermostat setbacks while considering other design variables. A second-order response surface is found to provide a reasonable fit to BEM simulation in- and out-of-sample data. The set point temperature is the most influential of the variables studied in decreasing long-term thermal comfort, while reducing HVAC electricity use. The thermostat setback has the strongest influence on thermal comfort in a hot-dry climate, while the most HVAC energy savings is able to be achieved in the mixed-humid climate zone. The results are tabulated for weighing the costs and benefits of TOU electricity rates for homes with different characteristics, in climate zones with air conditioning-dominate energy consumption.
\end{abstract}

Keywords: building energy modeling, response surface methodology, thermal comfort, time-ofuse pricing 


\section{Introduction}

In residential buildings, in which people spend on average $69 \%$ of their time [1], it is important to maintain a comfortable indoor environment. The properties of this indoor environment, including thermal comfort, have been linked to the health and productivity of occupants $[2,3]$. In mechanically-conditioned residential buildings which represent $83 \%$ of all residential buildings in the United States [4], the indoor environment is highly dependent on the operation of the heating, ventilation and air conditioning (HVAC) system. This is particularly important in the extreme warm and cold seasons in which the desired indoor conditions are much different than the outdoor weather conditions.

As a result, in part, of the high penetration and use of residential HVAC systems, particularly in warmer climate zones, the electric grid in these locations experiences large fluctuations in the electricity demand (MW) during the summer months. A graph of a summer electricity demand profile (MW)[5] is shown in Figure 1a for the ERCOT (Electric Reliability Council of Texas) electric grid, which includes hot, warm and mixed climate zones 2, 3 and 4 respectively as defined by the ASHRAE climate zones regions [6]. A significant portion of the peak loads in these areas is due to residential energy use, including HVAC systems. In ERCOT over 50\% of summer peak electricity loads (Figure 1b) can be attributed to residential buildings [7]. 


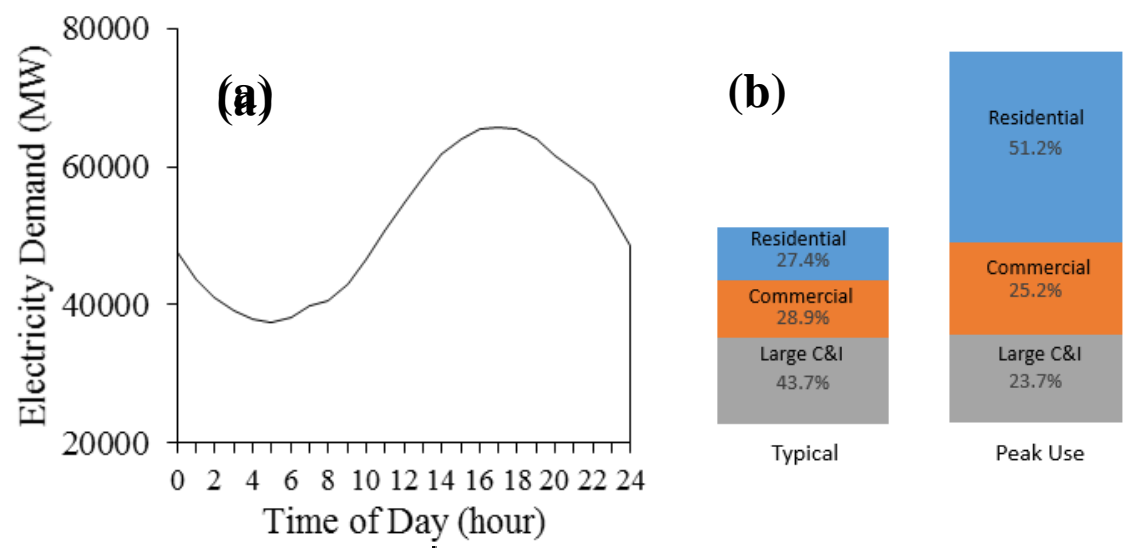

Figure 1: (a) Example of hourly fluctuation in electricity demand in ERCOT (Electric Reliability Council of Texas), which includes ASHRAE climate zones 2, 3 and 4, for a summer (cooling) season day (data:[5]); (b) Comparison of a typical electricity demand (MW) in ERCOT (Electric Reliability Council of Texas) for a typical day, and a summer day (left) during a peak-use time (right), indicating over $50 \%$ of peak demand is from residential buildings (data: [7]).

To address the variability in electricity demand, many electric utility companies have piloted or offer time-of-use electricity pricing (TOU) strategies for residential buildings, many of which are summarized in Newsham and Bowker (2010) [8]. Historically electricity rates schedules for residential buildings have not varied by time of use, but rather may be a constant rate, or tiered based on the amount of total electricity used throughout a one month period. TOU rates vary based on the time of day in which the electricity is used. These pricing structures include a lower "off-peak", and a higher "on-peak" rate $(\$ / \mathrm{kWh})$, with some rate structures also including a midlevel rate between the off- and on-peak times. Some also vary depending on whether it is a weekday or weekend. The TOU pricing trials that have achieved the highest energy savings and peak load reduction have been with homes that have "enabling technology," or technology that enables automatically reduction in electricity use when sent a pricing signal [8], rather than relying only on occupant-dependent changes. A common enabling technology is a smart thermostat, which is a programmable thermostat that communicates with the utility company pricing signals via two-way radio. This thermostat reduces electricity consumption during onpeak times by automatically introducing a setback in the set point temperature of the thermostat. 
Additional enabling technologies include smart home appliances, which can also reduce or defer electricity demand by altering their time-of-use of operation, discussed in Cetin et al. [9]. Since the change in HVAC system operation has a direct effect on indoor thermal comfort, this research is focused on smart thermostat-enabled HVAC operational changes.

For the adoption of TOU pricing structures, it is important that energy and/or cost savings are achieved to obtain participation from residential customers. However, it is also important to consider the effects these changes have on occupant comfort. In changing thermostat set point temperatures, thus changing the operation of the HVAC system, this also alters indoor environmental conditions. This includes both the indoor temperature and humidity, which affect occupant comfort [10]. The thermal comfort of occupants is a measure of occupant satisfaction with the indoor environmental conditions. A commonly used and widely accepted mathematical model of thermal comfort was developed by Fanger [11-12]. It is a function of dry-bulb air temperature $\left({ }^{\circ} \mathrm{C}\right)$, mean radiant temperature $\left({ }^{\circ} \mathrm{C}\right)$, air speed $(\mathrm{m} / \mathrm{s})$, and humidity $(\%)$, metabolic rate (met), and clothing insulation (clo) [13][10]. These factors are time dependent, but thermal comfort is assessed assuming steady-state conditions. This model uses these input parameters to predict the predicted mean vote (PMV) and the percent of people dissatisfied (PPD), with an acceptable PMV between -0.5 to 0.5 on a scale of -3 to 3 , and a maximum acceptable PPD of $10 \%$ on a scale of $1-100 \%$. Outside of these conditions is considered outside of the thermal comfort zone.

This model based on Fanger [11-12] is included in many national and international standards, including ASHRAE Standard 55 [10], International Standards Organization (ISO) 7730 [13], and EN 15251 [14]. A European adaptive thermal comfort model and an American adaptive thermal comfort model have been developed and included in EN 15251 and ASHRAE 55, respectively. 
The European adaptive thermal comfort model is based on either an exponentially weighted running mean of the daily outdoor air temperature, while the American adaptive thermal comfort model is based on the mean monthly outdoor temperature. As discussed in Attia and Carlucci [15], the standards generally agree with the suggestion of adoption of Fanger's model for mechanically heated and cooled buildings, while providing the option to use adaptive comfort models in naturally ventilated buildings [10] or in buildings without mechanical cooling [14]. As the large majority of residential buildings in the United States are mechanically conditioned, particularly in the hot summer periods, for this reason Fanger's PMV/PPD was chosen as the focus of this study. This model, however, only evaluates the thermal comfort for a single point in time.

Methodologies for defining the level and severity of thermal comfort or discomfort over a period of time have been proposed by a number of authors, many of which are summarized by Carlucci and Pagliano [16]. These include indices that evaluate the (a) percentage of time in or outside a threshold comfort range (e.g. [13][17-19]), (b) cumulative indices (e.g. [13][20]) in which thermal comfort values are added up over time, and (c) averaging indices (e.g. [21]) which calculate an average metric over a period of time.

Each long-term evaluation methodology has advantages and disadvantages. The Percent Outside Thermal Comfort Zone (POS) methodology (a), is able to capture upper and lower exceedances from the thermal comfort ranges; however, it suffers from the discontinuity occurring at the proposed thermal comfort zone limits. This implies an abrupt change in comfort perception of the occupants at this threshold, which is inconsistent with reality. This methodology also does not measure the severity of discomfort, only its occurrence. This methodology has been used significantly in previous studies (e.g. [22][16-18]) and is a simple way to evaluate long-term 
thermal comfort. Cumulative indices such as Accumulated PPD [13] do not have a discontinuity at the thermal comfort zone boundary. However, the value requires defining a reference cumulative value of what is an acceptable level of comfort over the given period of time. Average PPD, the average value of the PPD over the time period considered, also does not have a discontinuity at the thermal comfort zone boundary and can be compared to the existing ASHRAE 55 [10] defined recommended limit for acceptable PPD. It is calculated by averaging all of the measured PPD values over the time evaluated. Based on these advantages and disadvantages, for comparison to previous studies, POS is used in this research, and because Average PPD can be compared to current recommended thermal comfort limits, Average PPD is also utilized. The $P P D$ can be related to the $P M V$ using the equations defined by the Fanger model [12]. No known additional relationship between the different long-term thermal comfort indices, however, are known to have been developed.

To evaluate the effect of changes of building operations on thermal comfort, Cetin et al. [19] proposed a five-step methodology that uses building energy modeling simulations to develop a response surface (RSM)[23] that models the change in the POS response of a residential building due to operational and physical changes as a continuous function polynomial function. In this study this methodology was applied to assess a building's POS due to a one-hour demand response event in which the HVAC system is turned off. This study found that the RSM provided a reasonable fit to in-sample and out-of-sample BEM simulation data. The lower-order RSM function provides a model that enabled a quick evaluation of thermal comfort response of a building within a range of values of each of the design variables. Compared to running a building energy model simulation for each possible combination of variables desired to be studied, this methodology provides a way to quickly evaluate the effect of the change in a design 
variable of the building rather than running additional BEM simulations. Additionally, the function is used to take into account the inherent uncertainty in the design variables, by using Monte Carlo simulation to evaluate the probability that a given situation will exceed a given threshold values of acceptable thermal discomfort of the occupants. Cetin et al. [19] applied the proposed methodology to evaluate the thermal comfort response of a residential building to a one-hour demand response event but the methodology could be used to evaluate other the thermal comfort response of a building for other scenarios as well. Additionally, the methodology could be improved by evaluating multiple long-term thermal comfort indices, and also by comparing the trade off between energy use in comparison to the effect on occupant comfort.

Various techniques, including the RSM, have been proposed to simplify the evaluation of BEM by defining the relationship between a measured response and a set of design (input) variables. Specifically, the response surface methodology has been used in recent studies for the modeling of buildings and their components (e.g. [24-26]). Other methodologies include a simplified normative model [26], reduced order models [27-28], and artificial neural networks [29-31]. The response surface results in a function that can easily be used as input into probabilistic modeling, such as Monte Carlo simulation. In addition after its initial development, obtaining a model response is extremely fast. Also it has previously been shown to provide good agreement with in and out of sample data in building applications. For these reasons this methodology is used in this research in the evaluation of TOU pricing on different building types in different climate zones, on thermal comfort.

There are three main objectives of this study. The first main objective is to evaluate the use of the RSM constructed from BEM simulation data to determine long-term thermal comfort effects 
on a residential building. In this research, this methodology is applied to determine the effect of technology-enabled time-of-use pricing on thermal comfort in the cooling season (summer) for a range of climate regions, and building and operational characteristics. The studied homes have a smart thermostat that automatically sets back the thermostat set point temperature during peak energy price time periods. As a long-term thermal comfort index, this study uses the Average $P P D$ index, and also, it compares this to the POS index. Second, this study seeks to utilize the results of the RSM and probabilistic analysis to understand the influential design variables on long-term occupant thermal comfort. Third, this study aims to compare the thermal comfort levels resulting from the smart thermostat and TOU pricing, to the electricity use reductions that results from this change in operations. The results of this research are intended to be used for evaluating the costs (thermal discomfort) and benefits (energy reduction) due to TOU pricing for residential buildings with the flexibility of a model that provides a continuous function to evaluate thermal comfort changes due to operational and physical property changes within a specified range.

This research is organized into several sections. The Methodology section discusses the climate zones studied, baseline characteristics of the building energy models used, and the input design variables chosen. Each step of the five-step methodology used to evaluate the effects of TOU on long-term thermal comfort is then discussed. The Results and Discussion section describes the results of this methodology and analysis to achieve the three discussed objectives. To achieve the first objective, this section includes a check of the accuracy of the model developed by this methodology for in- and out-of-sample data. To achieve the second objective, this section then compares the level of influence of the studied variables on the thermal comfort indices and on the probability of exceeding a threshold level of discomfort using this model. Finally, to 
accomplish the third objective, the HVAC energy use is compared to the long-term thermal comfort indices, to show the relationship between energy use and comfort in each of the studied climate zones. This research concludes with Limitations and Conclusions sections, in which the limitations of the study and a summary of the findings, respectively, are discussed.

\section{Methodology}

To evaluate the effects of TOU on thermal comfort in different climate zones a building with same geometry was modeled while considering specifics of each climate. The five-step evaluation methodology includes: (1) design variable definition, (2) building energy modeling (BEM), (3) response surface development, (4) probabilistic evaluation using the response surface, and (5) result interpretation; each are discussed in order below.

Three climate zones are evaluated, including ASHRAE climate zone 4a (mixed-humid), 3a (hothumid), and 2b (hot-dry) [6]. A representative location was chosen within each of these climate zones for evaluation. These climates zones represent a significant portion of the residential buildings in the U.S. in warm and hot climate zones, totaling 63.1 million U.S. residential households. A summary of the descriptive characteristics of these locations is included in Table 1. The average number of cooling degree days (CCD) and average outdoor relative humidity in these climate zones throughout the year and in the summer period was determined based on Typical Meteorological Year (TMY) datasets developed using Class I weather station data [32]. The most recent set of TMY data was used, TMY3, which was created using the most recently available weather and solar data. This weather data source is commonly used for building energy modeling. 
Table 1: Climate Zones Characteristics and U.S. Residential Buildings

\begin{tabular}{l|llllll}
\hline Climate Zone & $\begin{array}{l}\text { ASHRAE } \\
\text { Climate } \\
\text { Zone }^{1}\end{array}$ & $\begin{array}{l}\text { Residential } \\
\text { Buildings } \\
\text { (millions) }\end{array}$ & $\begin{array}{l}\text { Location of } \\
\text { Study in } \\
\text { Climate Zone }\end{array}$ & $\begin{array}{l}\text { Annual } \\
\text { CCD } \\
\left(10^{\circ} \mathrm{C}\right)^{3}\end{array}$ & $\begin{array}{l}\text { Summer } \\
\text { CCD } \\
\left(10^{\circ} \mathrm{C}\right)^{3}\end{array}$ & $\begin{array}{l}\text { Summer } \\
\text { Average } \\
\text { RH }(\%)^{5}\end{array}$ \\
\hline \hline Mixed-Humid & $4 \mathrm{a}$ & 32.8 & Baltimore, MD & 2169 & 1870 & 70 \\
Hot-Humid & $3 \mathrm{a}$ & 17.0 & Austin, TX & 3046 & 2537 & 71 \\
Hot-Dry & 2b & 13.3 & Phoenix, AZ & 4064 & 3368 & 27 \\
\hline \\
${ }^{1}$ As defined by ASHRAE 90.1-2013[6] \\
${ }^{2}$ From Residential Energy Consumption Survey [4] \\
${ }^{3}$ CCD = Cooling Degree-Days with a reference temperature of $10^{\circ} \mathrm{C}$ \\
${ }^{4}$ Summer is defined as May 1 to September 30 \\
${ }^{5}$ From Typical Meteorological Year (TMY) weather data [32] \\
${ }^{5}$ RH = Relative Humidity (\%)
\end{tabular}

To represent a typical building, a single-story $204 \mathrm{~m}^{2}$ single family home with a forced-air central air conditioning system was used to evaluate the effects of HVAC operational changes on thermal comfort. This size is equal to the average size of a U.S. single family home based on the Residential Energy Consumption Database [4] for the three studied climate zones.

In the development of a building energy model, the building envelope properties, HVAC system specifications, and internal loads and schedules need to be defined. The properties of the building envelope were defined using the International Energy Conservation Code (IECC) [33], and include the insulation values for the walls, ceiling, and fenestrations, and the solar heat gain coefficient of the windows. These characteristics represent the minimum prescriptive values required by the IECC, thus the building model represents the characteristics common to newer buildings. Additional building properties were defined based on the Building America House Simulation Protocol [34] for new buildings. Previous research has also cited the need to adjust the moisture absorption capacity assumption of building energy model, particularly when evaluating indoor thermal comfort [34-36]; based on this research a value of 15 was used in the building energy model. The building systems include a single-stage residential HVAC system with external compressor and condenser unit and indoor air handling unit, with an air distribution system and duct system in the attic space. Cooling and heating are electric-based from a heat 
pump. Since the building is a single story house, the HVAC control is a single zone with standard on/off compressor and air handling unit fan [34]. The size of the HVAC system was fixed based on Manuel J [37] sizing calculations for each of the studied climate zones assuming a constant cooling set point and the mean values of the properties of the studied variables listed in Table 4. Internal loads are based on typical occupancy schedules and internal load schedules for residential buildings from the Building America Energy Simulation Protocol [34]. These building envelope and system properties are summarized in Table 2 .

Table 2: Residential Building Construction and System Properties by Climate Zone

\begin{tabular}{|c|c|c|c|c|c|c|c|c|}
\hline Climate Zone (\#) & Ceiling $^{1}$ & Wall $^{1}$ & Window $^{1}$ & SHGC $^{1}$ & $\begin{array}{c}\text { Exterior } \\
\text { Boundary } \\
\text { Conditions }\end{array}$ & $\begin{array}{l}\text { Window } \\
\text { Area }(\%)^{2}\end{array}$ & $\begin{array}{c}\text { HVAC } \\
\text { size }(k W)^{3}\end{array}$ & SEER $^{4}$ \\
\hline Mixed-Humid (4a) & R-38 & R-13 & U-0.35 & ב-- & All & & $\overline{12.3}$ & \\
\hline Hot-Humid (3a) & $\mathrm{R}-30$ & $\mathrm{R}-13$ & U- 0.50 & 0.30 & exterior & $15 \%$ & 15.8 & 13 \\
\hline Hot-Dry (2b) & $\mathrm{R}-30$ & $\mathrm{R}-13$ & $\mathrm{U}-0.65$ & 0.30 & walls & & 19.3 & \\
\hline
\end{tabular}

To define the time-of-use rate schedule, since time-of-use rates are implemented with the purpose of incentivizing peak load reduction, only the cooling period of the year is when TOU is applied. Based on the studied TOU pricing trials occurring in hot and warm climate zones, the length of study was limited to May $1^{\text {st }}$ to September $30^{\text {th }}$ for the cooling season (summer), paralleling many of the TOU rate schedule periods for the cooling season (summer) in the studied areas [8]. Of the studied TOU pricing trials, both two- and three-tier electricity pricing structures were used. In the chosen cities for use in this study, the optional time-of-use rate structures offered for residential buildings generally have a peak TOU summer rate that begins between 10:00 am and 2:00 pm, and ends at 8:00 pm. To parallel this timing, but to limit overestimation of the effect on thermal comfort, a two-tier rate structure was chosen such that the 
peak use rate occurs between 2:00 pm and 8:00 pm and the off-peak rate occurs between 8:00 $\mathrm{pm}$ and 2:00 pm. The time-of-use rate versus the standard rates used are shown in Table 3.

Table 3: Time-of-Use and Standard Summer Electricity Rate Schedule (May 1-September 30)

\begin{tabular}{c|cc|c}
\multicolumn{2}{c}{ Time-of-Use } & \multicolumn{2}{c}{ Standard } \\
\hline \hline Off-Peak & $8 \mathrm{pm}-2 \mathrm{pm}$ & All Times & $12 \mathrm{am}-12 \mathrm{am}$ \\
On-Peak & $2 \mathrm{pm}-8 \mathrm{pm}$ & &
\end{tabular}

\section{(1) Design Variable Definition: Building Operations Variables}

To develop a response surface several design variables $\mathbf{X}=\left\{X_{1}, X_{2}, \ldots X_{n}\right\}$ are considered, including the degrees of indoor temperature setback in cooling mode during on-peak times. These design variables are used as inputs to build and define the response surface. It is desired that the model allow for adjustments for a range of occupant-controlled parameters, as these parameters are adjustable without making modifications to the building structure. These parameters include the thermostat cooling (summer) set point temperature $\left({ }^{\circ} \mathrm{C}\right)$, the degrees of setback temperature $\left({ }^{\circ} \mathrm{C}\right)$ during on-peak times, and the air exchange rate $\left(\mathrm{hr}^{-1}\right)$. The set point temperature and degrees of setback temperature can be adjusted by changing the thermostat; the air exchange rate varies based on the natural and mechanical ventilation, and the weatherization of a home. The thermal mass of the home is the fourth design variable. Thermal mass can vary depending on the type of building construction and the amount, thickness of the interior partition walls and amount of objects or furniture placed and the home. Variations in the thermal mass of a building can affect how quickly a building's indoor environmental conditions respond to set point temperature changes, and thus are important to also include in this study. The effect of thermal mass on buildings has been discussed in previous research [38-41], however, most have focused on commercial rather than residential building applications.

Each design variable requires an upper and lower bounds of which the variable is evaluated and the model is valid in the developed response surface. The upper $\left(x_{t h} h_{i g}\right)$ and lower 
$\left(x_{t, 20 w}\right)$ bounds of the set point temperatures were chosen to be within the limits of the summer thermal comfort zone as defined by ASHRAE 90.1 [6]. The degrees of setback temperature was chosen to represent the extreme minimum (no setback), to maximum setback from previously conducted demand response and time-of-use rate trials [42]. The upper and lower bounds of the air exchange rate were chosen to cover a range of values common in newer buildings [43]. Thermal mass varies depending on the amount of interior walls and furniture inside a residential building. The values used are measured in $\mathrm{kJ} /{ }^{\circ} \mathrm{C}-\mathrm{m}^{2}$ and include interior drywall used for the external and internal walls and ceiling. The lower bound of the thermal mass equates to $13 \mathrm{~mm}$ drywall on the interior side of the exterior walls, on the ceilings and on the interior partition walls. These variables are summarized in Table 4.

Table 4: Design variables used to create thermal comfort response surface model

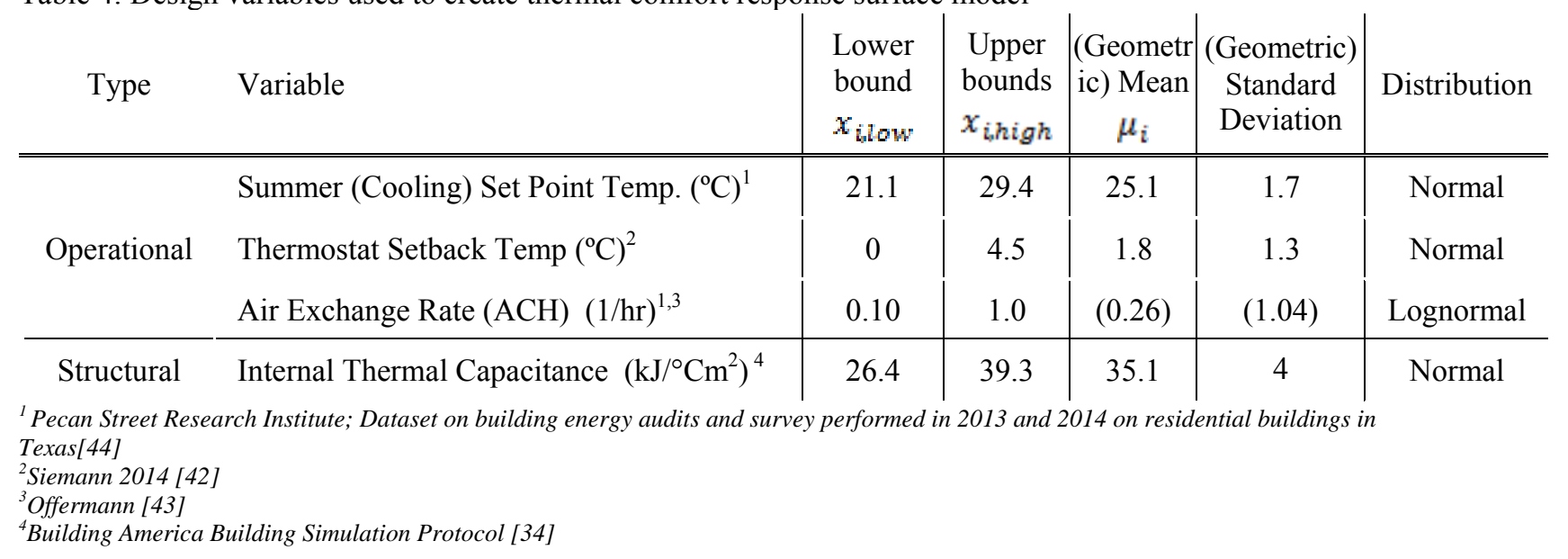

\section{(2) Building Energy Modeling (BEM)}

Using BEM software EnergyPlus version 8.1[45], the response of the studied building was evaluated using a $3^{\mathrm{n}}$ full factorial experimental design for the four sets of design variables. For each climate zone, this amounts to 81 trials, or a total of 243 BEM simulations. This includes a simulation at each combination of the $n$ design variables $\left(X_{i} ; i=1\right.$ to $\left.n\right)$ at three design points, $x_{i, h i g h}, x_{i, l o w}$ and a center point. The output variables of BEM, including indoor 
temperature, $T_{a}\left({ }^{\circ} \mathrm{C}\right)$, mean radiative temperature, $T_{M R}\left({ }^{\circ} \mathrm{C}\right)$, operative temperature $T_{o},\left({ }^{\circ} \mathrm{C}\right)$ and humidity ratio $H R(\%)$ are used to evaluate the values of Average PPD (Equation 1a) and the POS (Equation 1b-c) for all simulations. In these equations $k$ is the climate zone, $h$ is the hour being evaluated, and $h_{\text {tot }}$ is the total number of hours. Within the thermal comfort zone $\left(c_{h}=0\right)$ is defined as a PPD value of less than 10 or a PMV between -0.5 and 0.5 per ASHRAE 55 (2010). PPD, a function of the input variables, was calculated based on the equations in by ASHRAE 55 in Appendix D [10]. The output of the BEMs was combined and a MATLAB code was developed to calculate Average PPD and POS for each trial.

$$
\begin{gathered}
\text { Average PPD } D_{k}=\left(\frac{\sum_{1}^{h_{\text {tot }}} P P D\left(T_{a,} T_{M R}, T_{o}, H R\right)_{h}}{h_{\text {tot }}}\right)_{k} \\
\operatorname{POS}_{k}=\left(\frac{\sum_{1}^{n} c_{h}}{h_{\text {tot }}}\right)_{k} \\
c_{h}=\left\{\begin{array}{c}
1 \leftarrow \text { (outside thermal comfort zone) } \\
0 \leftarrow \text { (inside thermal comfort zone) }
\end{array}\right.
\end{gathered}
$$

\section{(3) Response Surface Development}

Based on the results of the building energy modeling simulations, a response surface $S(\mathbf{X})$ (Equation 2) is created. This response function is defined using linear and nonlinear terms made up of the $n$ design variables $\mathbf{X}=\left\{X_{1}, X_{2}, \ldots X_{n}\right\}$ listed in Table 5, and a set of coefficients, $b_{i}(i=$ 1 to $n)$ for linear variation and $b_{i j}(i, j=1$ to $n)$ for quadratic variation. These are discussed in Meyer et al [46], and Khuri and Mukhopadhyay [47]. Least-squares regression is used with the selected design variables and the results of the BEM simulations to develop the nonlinear, second-order response surface function. To evaluate the goodness of fit of the model, the $R^{2}$ (coefficient of determination) value is used. Evaluation of goodness of fit was conducted on both in-sample and out-of-sample data which are within the range of the upper and lower bounds of 
the design variables considered. Out-of-sample data was developed using a random number generator to create values for each of the design variables between the upper and lower bounds, $x_{i, \text { high }}$, and $x_{i, \text { low }}$, then BEM was evaluated for each of these trials and compared to the modelpredicted values. Terms in $S(\mathbf{X})$ that have a significant influence on the response surface are defined as those in which the p-value is less than 0.0005 .

$$
S(\mathbf{X})=b_{o}+\sum_{i=1}^{n} b_{i} X_{i}+\sum_{i=1}^{n} \sum_{j=1}^{n} b_{i j} X_{i} X_{j}
$$

\section{(4) Probabilistic Evaluation Using the Response Surface}

The response surface model developed following BEM simulations is an approximate representation of a real-world based situation based on assumptions and approximations. To address uncertainty in the design variables, Monte Carlo simulation [48] is used with the distributions of the design variables specified in Table 4 to determine the Average PPD for each of the three climate zones for the typical home studied. The distribution parameters for each of the design variables were determined based on data collected from previous studies, as summarized in Table 4. An Anderson-Darling test was performed to determine the best distribution fit for the data for each of the design variables based on the collected data. This is compared to a threshold acceptable level of PPD, $P P D_{a c c}$, to determine the probability that the Average PPD will exceed this threshold value (Equation 3), where $S(\mathbf{X})$ is the response surface function developed in Step 3. In this evaluation it is assumed that all the design variables are independent random variables. The $P P D_{a c c}$ is evaluated as $5 \%, 10 \%$ and $15 \%$. The accuracy of $P_{f}$ estimates based on MC simulations increases with the number of simulations, which was set at a maximum of 100,000 simulation. 


$$
P_{f, P P D}=P P D_{a c c}-S(\mathbf{X})
$$

\section{Results and Discussion}

The results of research are divided into three different sections to specifically address each of the three objectives. The first section addresses the evaluation of the RSM to create a continuous function that represents the long-term thermal comfort performance of a building due to changes in the considered design variables. The second section utilizes the resulting model and probabilistic analysis to evaluate the influence of the design variables and the terms in the RSM model on long-term thermal comfort. The third section compares HVAC energy use with the long-term thermal comfort indices to evaluate the costs and benefits of smart thermostat technology-enabled time-of-use pricing.

\section{Model Evaluation to Predict Thermal Comfort}

The coefficients for the response surfaces built for each of the studied climate zones is included in Table 1. The second order response surface model shows a stronger fit than a first order model, with a coefficient of determination $\left(\mathrm{R}^{2}\right)$ value of 0.995 to 0.997 for in-sample data fitting in each of the studied climate zones. Table 5 shows the coefficients and p-values for each of the terms for each of the three locations of study for both the Average PPD and the POS. 


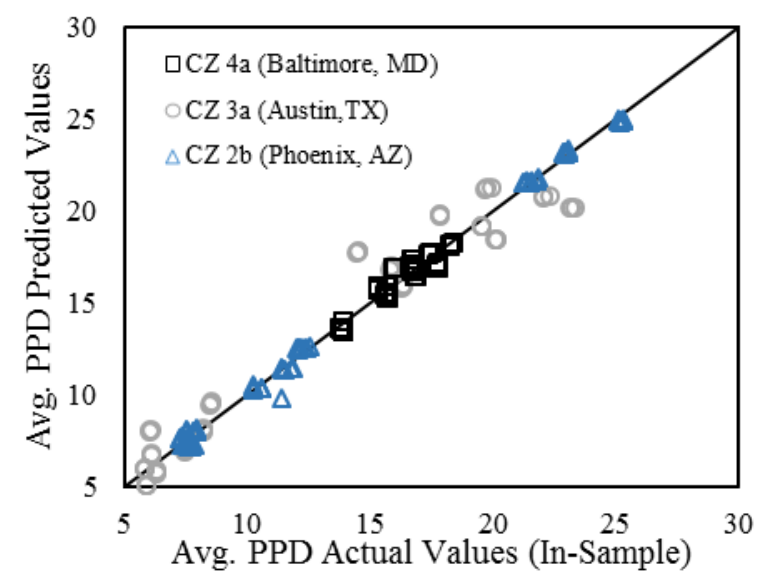

(a)

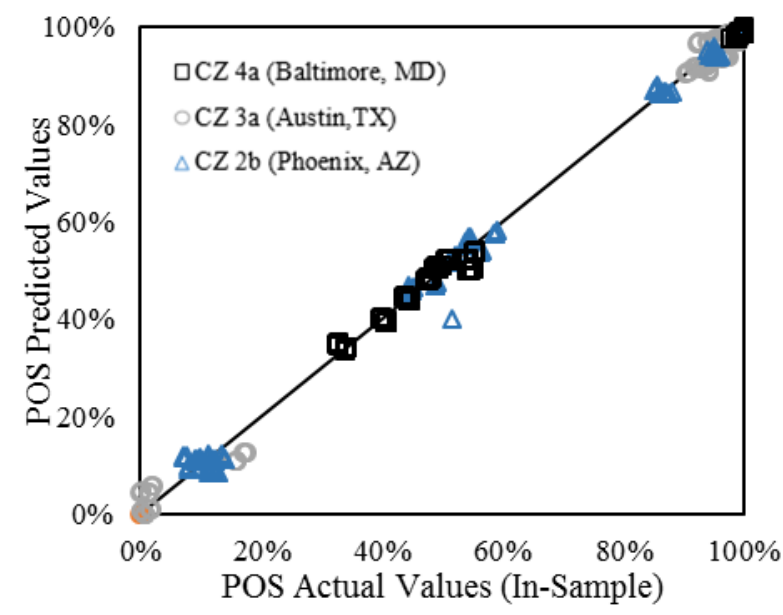

(c)

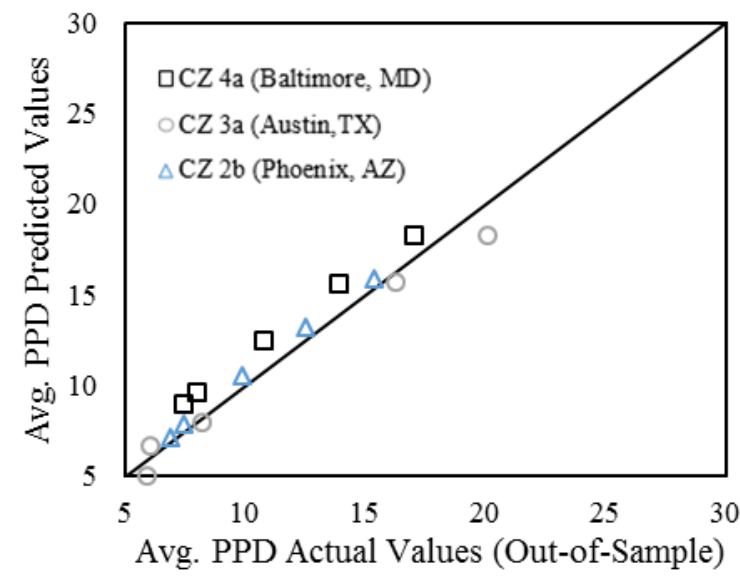

(b)

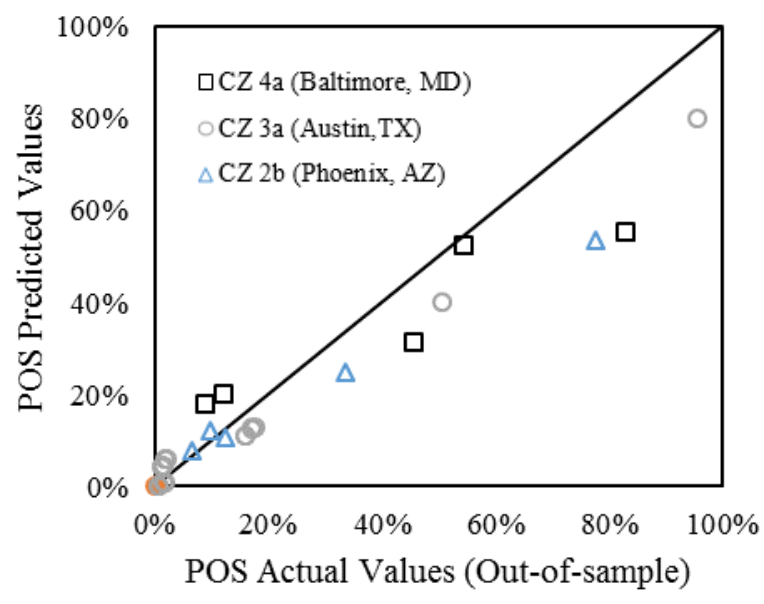

(d)

Figure 2: Parity plots comparing the model-predicted values of the Average PPD and POS for in-sample (a and c) and out-of-sample ( $\mathrm{b}$ and d) data. Note: $\mathrm{CZ}=$ climate zone, $\mathrm{PPD}=$ Percent of people dissatisfied, $\mathrm{POS}=$ percent outside the thermal comfort zone.

\section{Influential Variables and RSM Terms on Thermal Comfort}

In all of the studied climate zones, increases set point temperature and increases in the thermostat setback temperature also increase the Average PPD and POS long-term thermal comfort indices. Increased discomfort due to increased set point temperatures is consistent with ASHRAE 55 (2010)[10], in which the percent of people dissatisfied increases with increasing indoor temperatures. In all of the studied climate zones, an increase in thermal mass over the range of values studied has little effect on the Average PPD and POS. A home with a larger thermal mass 
has a lower rate of increase in indoor temperature because a higher thermal mass introduces a thermal lag or time delay in the flow of heat from exterior to interior. Thus if the thermostat is set back it can take more time for a higher thermal mass building to increase in temperature to where the occupants are uncomfortable. However, the thermal mass in the modeled buildings represents the typical thermal mass of a newly built home. This thermal mass and variation in thermal mass is small in comparison to what has been used to effectively affect rate of increase in temperature, and in effect the thermal comfort in residential buildings in previous studies (e.g.[49-51]). In all of the studied climate zones an increase in air exchange rate, increases the Average PPD and POS. This is consistent with previous findings (e.g. [52-53]). If an increased amount of unconditioned outdoor air enters into the indoor environment due to a higher air exchange rate, this can increase indoor temperatures faster, resulting in a longer period of time at a higher temperature.

The most significant second-order RSM terms vary by the climate zone in which the building is located. Terms in the response surface with significant influence (p-value less than 0.0005) on the thermal comfort indices are shown to have a p-value of 0.000 in Table 5. The set point temperatures and squared set point temperature were significant influences for both Average $P P D$ and $P O S$ in all of the studied climate zones. The degree of setback term was significant for the POS in climate zone 4a (mixed-humid), and thermal mass term in climate zone $2 \mathrm{~b}$ (hot-dry). Air exchange rate has the most influence in Climate Zones $3 \mathrm{a}$ and $2 \mathrm{~b}$. Additionally several of the reaction terms were significant.

Degrees of Setback and Set Point Temperature Influence on Thermal Comfort In evaluating the influence of the degrees of setback on thermal comfort, the Average PPD and the POS are compared with a constant set point temperature with zero degrees of setback, at each 
of the different design scenarios. At a degree of setback of zero, this represents a constant set point temperature regardless of the peak pricing. Figure 3 shows that the number of degrees of setback has non-linear influence on the long-term thermal comfort indices. Each of the lines in Figure 3 represents a different set point temperature and is labeled as such.

The degrees of setback during the on-peak times most strongly influences the thermal comfort indices in Climate Zone 2b (hot-dry). A 4 degree setback increases the Average PPD by $3.5 \%$ to $4.5 \%$, and $5 \%$ to $10 \%$ for the POS in this climate zone. In a hot climate with the highest number of cooling degree days in comparison to the other studied climates, this is a reasonable result. With a higher outdoor temperature, this will cause the building's indoor temperatures to increase faster during the setback times, as the building absorbs more solar radiation and transfer heat to the interior with a higher interior to exterior temperature gradient. The greatest change in the Average $P P D$ is due to changes in the degrees of setback temperature when the set point temperature is lower, while the greatest difference in POS occurs at higher set point temperatures. This represents a difference in results that varies based on the long-term thermal comfort index being used, and is discussed further in the comparison of the two thermal comfort indices in the section below.

Changes to the set point temperature have the strongest influence on thermal comfort in the hot climate zones (2b, hot-dry and 3a, hot-humid) (Figure 3). The Average PPD varies by approximately $17 \%$ across a range of $5^{\circ} \mathrm{C}$ in set point temperature for Climate Zone $2 \mathrm{~b}$ (hot-dry), and $19 \%$ for Climate Zone $3 \mathrm{a}$ (hot-humid). These variations in thermal comfort are $56 \%$ and 77\% more, respectively, than for Climate Zone 4a (mixed-humid). Similarly, the POS varies by approximately $69 \%$ across the evaluated indoor set point temperatures for Climate Zone $2 \mathrm{~b}$ (hot- 
dry), and $65 \%$ for $3 a$ (hot-humid). These variations are $27 \%$ and $20 \%$ more, respectively than for Climate Zone 4a (mixed-humid). 


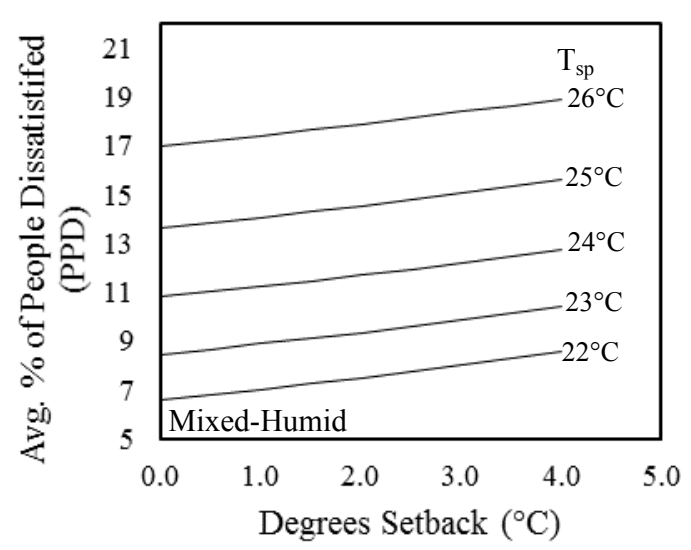

(a)

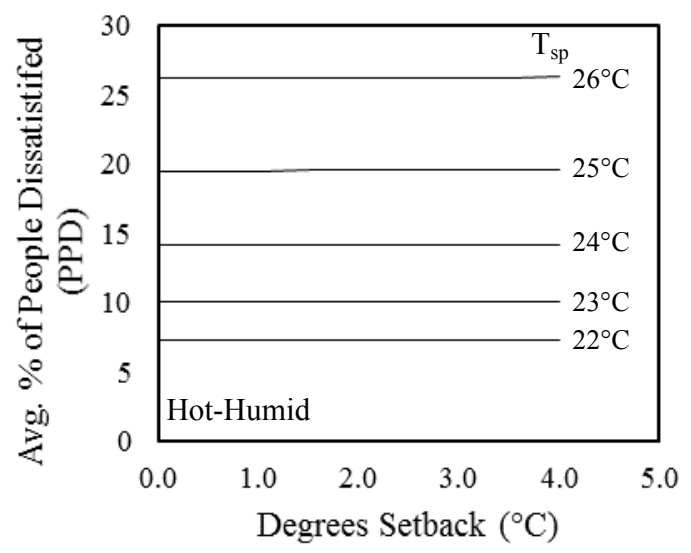

(c)

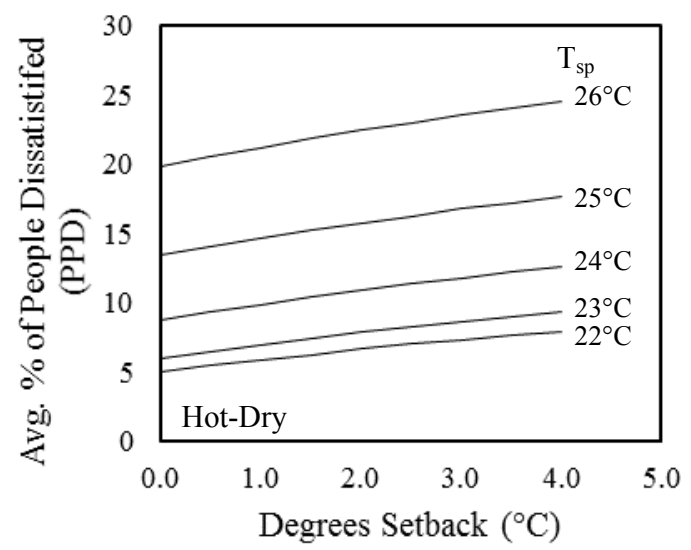

(e)

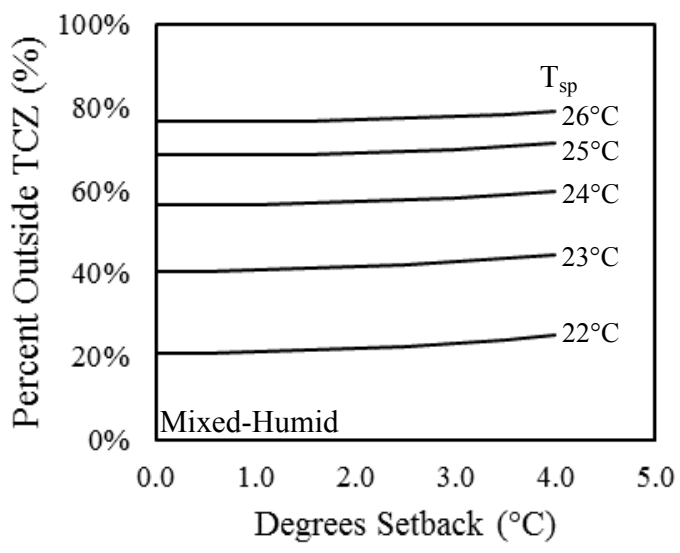

(b)

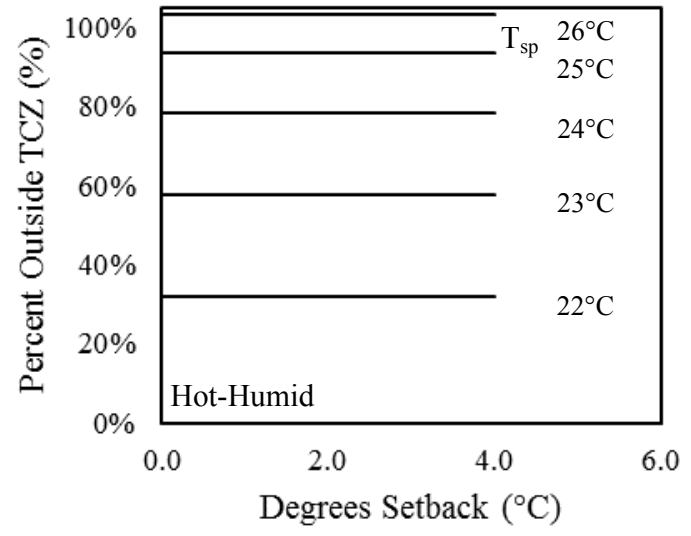

(d)

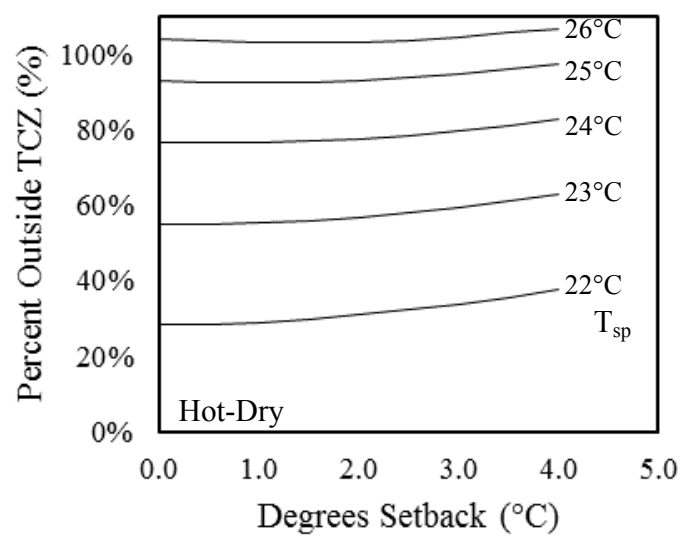

(f)

Figure 3: Influence of degrees of setback temperature on the Average PPD and POS at a range of indoor set point temperatures for Climate Zone 4a (mixed-humid) (a,b), 3a (hot-humid) (c,d), and 2b (hot-dry)(e,f).

Note: Each line represents a set point temperature; a constant value for ACH of $0.4 \mathrm{~h}^{-1}$ and thermal capacitance of $35 \mathrm{~kJ} /{ }^{\circ} \mathrm{C}-\mathrm{m}^{2}$ are used in the creation of these graphs. 
This also shows that an indoor set point of $22^{\circ} \mathrm{C}$ to $24^{\circ} \mathrm{C}$ at varying set back temperatures will generally ensure that the indoor environmental conditions will remain below the threshold value of Average PPD of 10\%, as defined by ASHRAE 90.1[6]. Thermostat set point temperatures greater than $24^{\circ} \mathrm{C}$, a common thermostat set point for the summer (cooling) season for a mechanically-conditioned home, were above the $10 \%$ threshold with varying ranges of degrees of setback temperatures.

Probability Analysis: Probability of exceeding threshold acceptable level of discomfort To look at the effects of a large-scale implementation of time-of-use pricing, probabilistic analysis allows for evaluation of the effects on a set of homes with a distribution of setback temperatures, and the other studied design variables. Assuming an adoption rate of the degrees of setback temperature for time-of-use pricing from Siemenn [42], and the probability distributions of the design variables specified in Table 2, Monte Carlo simulation results are shown in Figure 4. For homes in the hot-dry climate zone a lower percentage of the homes meets the suggested maximum $10 \%$ PPD as compared to the mixed-humid and mixed-hot climates. For homes in the hot-dry climate zone approximately $35 \%$ and $60 \%$ of single family homes have an Average PPD of $10 \%$ and $15 \%$ respectively, where as in the hot-humid and mixed-humid climate zones, $45-65 \%$ and $80 \%$ of homes have an Average PPD of $10 \%$ and $15 \%$. The hot climate zones also have a longer tail of homes at high values of Average PPD than the mixed climate zone. 

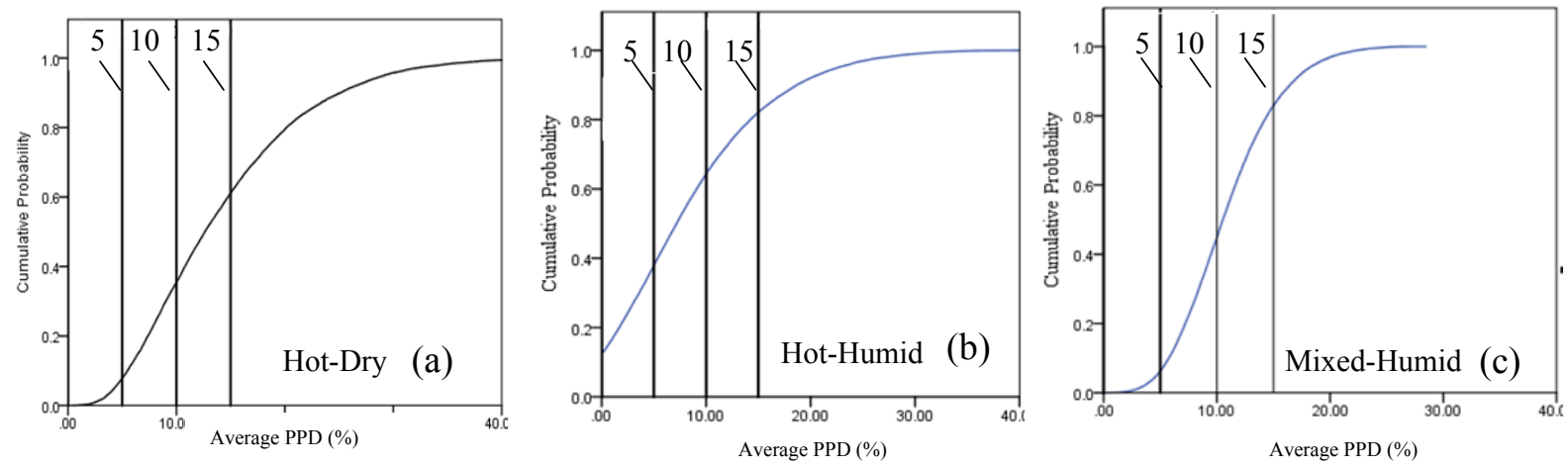

Figure 4: Cumulative probability of the Average Percent of People Dissatisfied (Average PPD) (\%) for Climate Zone (a) 2b (hot-dry), (b) 3a (hot-humid), and (c) 4a (mixed-humid) resulting from Monte Carlo Simulation

\section{Comparison of Thermal Comfort Indices}

In the development and evaluation of the effect of the considered design variables on Average $P P D$ and POS, the use of one thermal comfort index versus another is important to consider. Figure 5a shows a comparison of the thermal comfort indices at an $\mathrm{ACH}$ of $0.4 \mathrm{~h}^{-1}$ and a thermal mass of $35 \mathrm{~kJ} /{ }^{\circ} \mathrm{C}-\mathrm{m}^{2}$, with variations in set point temperature and degrees of setback. Figure $5 \mathrm{~b}$ shows the results of the BEM simulations used to create the response surface. The threshold acceptable level of PPD per ASHRAE 55 [10] is equal to $10 \%$, which equates to a POS of between approximately 45 and $80 \%$ depending on the climate zone and the values of the design variables used. This also shows that the POS evaluation can only evaluate thermal comfort up to the equivalent Average PPD of $26-27 \%$. After this level, the POS is nearly $100 \%$ or slightly over predicts the $100 \%$ value, whereas the Average PPD can continue to differentiate the level of thermal comfort at higher ranges of indoor temperature conditions. 


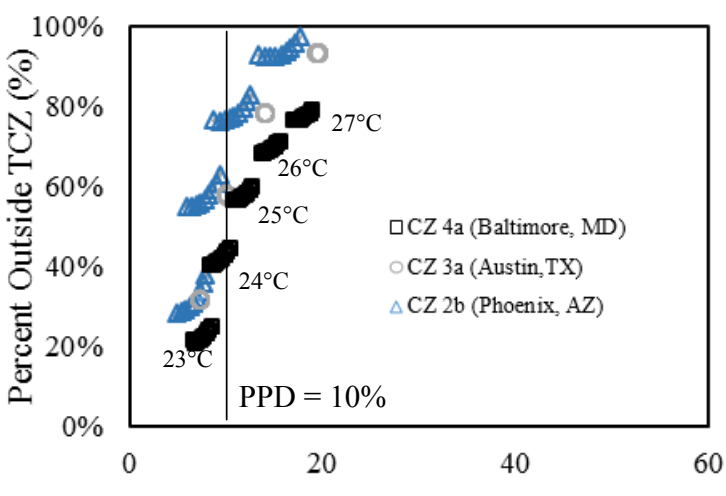

Avg. Percent of People Dissastified

(Averge PPD)

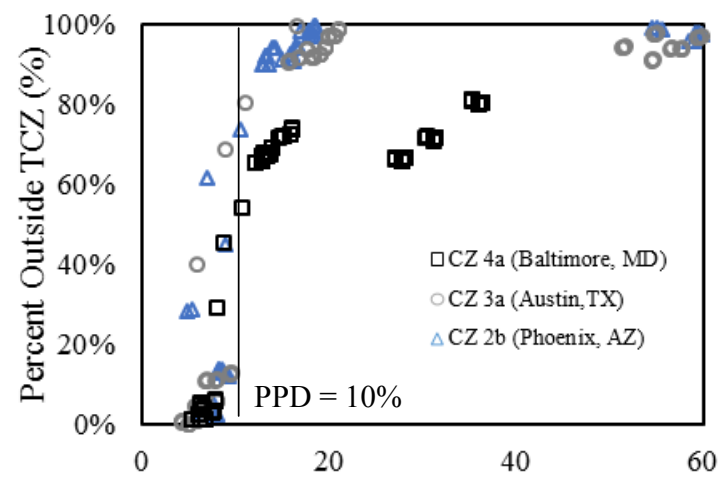

Avg. Percent of People Dissastified

(a)

(b)

Figure 5: Comparison of Percent of People Dissatisfied (\%) and Percent Outside the Thermal Comfort Zone for Climate Zone 4a (mixed-humid), 3a (hot-humid), and 2b (hot-dry) using the RSMs (a), and for all data points used to develop the RSM from building energy modeling (b)

Note: In Figure 5a each cluster of points has a set point temperature as labeled; the variation in the values in the clusters is due to the change in degrees of setback temperature with a higher degree of setback temperature representing the points on the right of each cluster; a constant value for ACH of $0.4 \mathrm{~h}^{-1}$ and thermal capacitance of $35 \mathrm{~kJ} /{ }^{\circ} \mathrm{C}-\mathrm{m}^{2}$ are used.

\section{Comparison of Energy Use and Thermal Comfort:}

The energy use of the HVAC system servicing the studied residential building is compared with the two long-term thermal comfort indices for each of the studied climate zones. Similarly using the response surface methodology, HVAC use is related to the studied design variables. The values of these coefficients and p-values are included in Table 6. Similar to the thermal comfort indices, HVAC use is most influenced by the set point temperature in all of the studied climate

zones.

Table 6: HVAC energy use ( $\mathrm{kWh})$ coefficients and $\mathrm{p}$-values ${ }^{1}$ of the second-order response surface model

\begin{tabular}{|c|c|c|c|c|c|c|c|c|c|c|c|c|c|c|c|c|}
\hline & $\begin{array}{l}\text { Cli- } \\
\text { mate }\end{array}$ & $\begin{array}{c}\text { Inter- } \\
\text { cept }\end{array}$ & $\begin{array}{c}\mathrm{T}_{\mathrm{SP}} \\
\left({ }^{\circ} \mathrm{C}\right) \\
\end{array}$ & $\begin{array}{l}\mathrm{T}_{\mathrm{SB}} \\
\left({ }^{\circ} \mathrm{C}\right) \\
\end{array}$ & $\begin{array}{c}\mathrm{TM} \\
\left(\mathrm{kJ} /{ }^{\circ} \mathrm{C}-\mathrm{m}^{2}\right)\end{array}$ & $\begin{array}{l}\mathrm{ACH} \\
(1 / \mathrm{hr}) \\
\end{array}$ & $\begin{array}{l}\mathrm{T}_{\mathrm{SP}} * \\
\mathrm{~T}_{\mathrm{SB}} \\
\end{array}$ & $\begin{array}{l}\mathrm{T}_{\mathrm{SP}} * \\
\mathrm{TM} \\
\end{array}$ & $\begin{array}{r}\mathrm{T}_{\mathrm{SP}} * \\
\mathrm{ACH} \\
\end{array}$ & $\begin{array}{l}\mathrm{T}_{\mathrm{SB}} * \\
\mathrm{TM} \\
\end{array}$ & $\begin{array}{l}\mathrm{T}_{\mathrm{SB}} * \\
\mathrm{ACH} \\
\end{array}$ & $\begin{array}{l}\mathrm{TM}^{*} \\
\mathrm{ACH} \\
\end{array}$ & $\mathrm{T}_{\mathrm{SP}}^{2}$ & $\mathrm{~T}_{\mathrm{SB}}^{2}$ & $\mathrm{TM}^{2}$ & $\mathrm{CCH}^{2}$ \\
\hline \multirow{3}{*}{$\begin{array}{l}\text { Coeff- } \\
\text { icient }\end{array}$} & 4 & 21382 & - & - & 6842 & -2.679 & 6.228 & 0.041 & 9 & 0.055 & 9 & 170 & & & & \\
\hline & & & & & & & & & & & & & & & & \\
\hline & $2 \mathrm{~b}$ & & .4 & -47.91 & 19 & 740 & -5.7 & 0. & -21.77 & -0.293 & -231.5 & -1.397 & 10.775 & 24.941 & -0.128 & -6.599 \\
\hline \multirow{3}{*}{$\begin{array}{c}\mathrm{P}- \\
\text { value }\end{array}$} & 44 & & & & & & & & & & & & & & & 0.517 \\
\hline & & & & & & & 0.5 & & & & & & & & & 0.000 \\
\hline & $2 \mathrm{~b}$ & 0.000 & 0.000 & 0.281 & 0.646 & 0.000 & 0.000 & 0.844 & 0.065 & 0.481 & 0.000 & 0.719 & 0.000 & 0.000 & 0.775 & 0.936 \\
\hline
\end{tabular}

$T_{S P}=$ Set point temperature, $T_{S B}=$ Setback temperature, $T M=$ thermal mass, $A C H=$ air exchange rate

$2 b=$ Hot-dry (Phoenix, AZ), 3a= hot-humid (Austin, TX), $4 a=$ mixed-humid (Baltimore, MD)

${ }^{1}$ If less than 0.0005 , the $p$-value is shown as a zero value 
Figure 6 shows the comparison of the HVAC energy use to the Average PPD and POS at an $\mathrm{ACH}$ of $0.4 \mathrm{~h}^{-1}$ and a thermal mass of $35 \mathrm{~kJ} /{ }^{\circ} \mathrm{C}-\mathrm{m}^{2,}$ with variations in set point temperature and degrees of setback. Each cluster of data points has a set point temperature and are labeled as such. The variation in the values in the clusters is due to the change in degrees of setback temperature $\left(0-4^{\circ} \mathrm{C}\right)$ with the highest degree of setback being the points with the highest thermal comfort dissatisfaction.

In Climate Zone 2b (hot-dry), the HVAC energy use is highest, followed by Climate Zone 3a (hot-humid) and 4a (mixed-humid). This is consistent with the values of the cooling degree days listed in Table 1. The thermal comfort of occupants decreases as the HVAC use increase, however this trend is not linear and depends on which long-term thermal comfort index is used. As the indoor set point temperature increases, and the degrees of setback increases, the amount of HVAC energy use decreases. An increase in the number of degrees of setback causes the greatest decrease in HVAC energy use in the mixed-humid climate as compared to the other studied climate zones. This is likely due to the less extreme outdoor temperatures and solar radiation in the mixed-humid climate that would not heat the residential building as quickly during the peak use time when the set point temperature is higher. An increase in set point temperature also causes the least increase in occupant dissatisfaction in the mixed-humid climate zone compared to the other studied climate zones. 


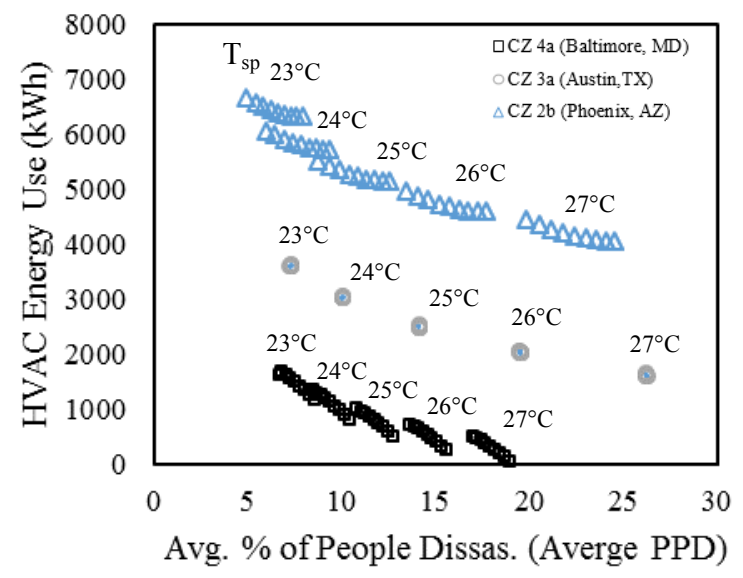

(a)

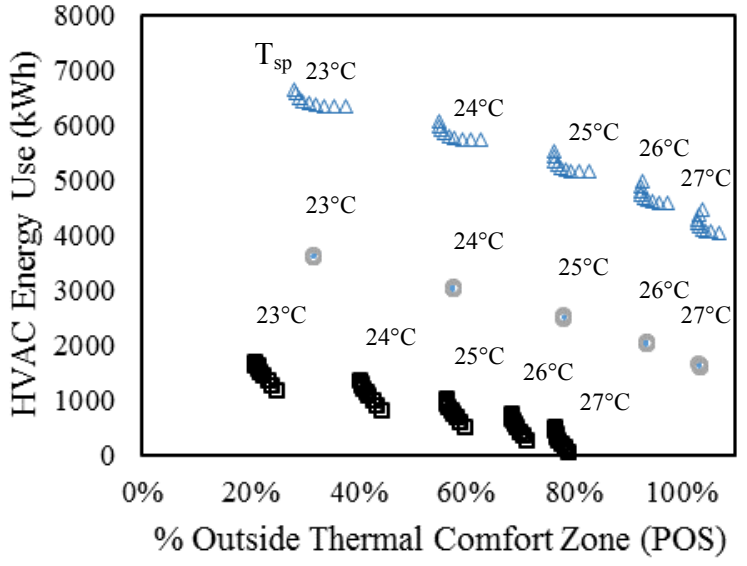

(b)

Figure 6: HVAC energy use compared to the long-term thermal comfort indices Average PPD(a) and POS (b) for Climate Zone 4a (mixed-humid), 3a (hot-humid), and 2b (hot-dry).

Note: Each cluster of points has a set point temperature as labeled; the variation in the values in the clusters is due to the change in degrees of setback temperature; a constant value for ACH of $0.4 h^{-1}$ and thermal capacitance of 35 $\mathrm{kJ} /{ }^{\circ} \mathrm{C}-\mathrm{m}^{2}$ are used.

\section{Study Limitations}

There are several limitations to this study. This research is limited to the study of the thermal comfort of mechanically-conditioned, residential buildings. In support of the selected type of buildings, mechanically conditioned residential buildings are most commonly found in the United States, and represent a large majority of the residential building stock [4]. Air conditioning use is also predicted to increase in use in future years throughout the world [54]. Naturally ventilated buildings are also common, particularly in European countries, and can be evaluated using the adaptive thermal comfort model. Due to the lack of an HVAC system it is likely that these buildings are more strongly affected by building construction characteristics and climate variations, however, the focus of this study is on the effects of changes in HVAC operations and resulting thermal comfort due to TOU pricing. Since HVAC loads are a significant portion of the peak energy use in the United States and are often targeted for TOU pricing, focusing on mechanically conditioned buildings is justifiable. 
This study is also focused on single family homes rather than multi-family properties. Single family homes were chosen for this research as they are the most common form of the mechanically conditioned residential building stock in the U.S. Differences between single family and multi-family include that multi-family residential buildings do not interface with the exterior on all sides and thus may affect the HVAC performance characteristics [55] and resulting thermal comfort. The single family home size and dimensions are also constant and not varied, as are other variables that are assumed as constant values in this study. The addition of an increasing number of design variables using a full factorial design significantly increases the number of BEM simulations needed to create the response surface. This study is limited in the design variables evaluated. However, this study targeted design variables that can have an effect on thermal comfort and that vary across the residential building stock, without suggesting occupant schedule change requirements, or the need to modify occupant behavior. Factors of the building's construction, systems, occupancy schedules, and internal loads, and different time-ofuse rate schedules may be evaluated as additional design variables in future work." Additional limitations also arise from the use of building energy modeling, as a building energy model is a simplification of a real-world building. However, significant effort has been done to validate the assumptions in the building energy model [34]. It assumes a single zone HVAC model in which a single temperature represents the temperature of the interior space when this may not necessarily be the case. This does not take into account temperature distributions or stratification which may affect thermal comfort within the studied zone [56-58]. If this methodology is applied to a commercial building or residential building with multiple HVAC systems and zones, multiple zones' thermal comfort would need to be considered. It is also assumed that the velocity of the cooling air provided by the HVAC is within the acceptable range 
per ASHRAE 55 [10]. It is also assumed that the HVAC system is functioning properly without any faults or inefficiencies and is properly sized using Manual J. An improperly sized HVAC system or an HVAC system with faults may affect the energy use and length of time the HVAC is on $[59][55]$.

The performance of an HVAC system and a building is highly dependent on external conditions. The TMY3 weather files [32] were used to evaluate the effect of thermal comfort. TMY weather files are the most commonly used form of weather data for energy modeling and were thus deemed appropriate for use in this study. However, TMY weather data does not take into account extreme weather conditions that have been found to be increasingly common occurrence, due to climatic changes [56]. This may affect that TOU pricing setbacks' influence on thermal comfort.

The thermal comfort model and long-term indices used also have limitations, many of which are discussed in Carlucci et al. [16]. The amount of clothing worn by occupants and the level of activity affect the location of the thermal comfort zone and thus the predicted level of comfort experienced by occupants. The thermal comfort model chosen for this research, based on the Fanger model [11-12] also assumes steady-state conditions. With a change in the indoor setpoint temperature due to a setback in temperature when the HVAC is in cooling mode, a residential building may not necessarily be operating under steady-state conditions. More recently, it has been suggested that other methodologies may be used to evaluate thermal comfort. However, as pointed out in Wong et al. [62], there are limited available models that provide a similar predictor of thermal sensation. Adaptive thermal comfort models, including those previously discussed, the American and European adaptive thermal comfort models in standards ASHRAE 55 [10] and EN 15251 [14], are based on the outdoor daily or monthly temperatures, and do not 
assume steady-state conditions. While these models are generally applied to naturally conditioned spaces, in the context of the use for a residential building where the indoor set point is changed, the application of this thermal comfort model may be appropriate. Adaptive thermal comfort models for commercial and residential buildings under TOU pricing have been discussed in recent literature (e.g. [60-61]). If an adaptive thermal comfort model was used as the basis for the thermal comfort long-term indices in this research, most likely the level of thermal discomfort experienced by occupants would be predicted to be lower. This comparison of thermally comfortable indoor conditions is well described and shown in Fig. 10 of Attia and Carlucci [15].

The thermal comfort indices also evaluates the indoor thermal comfort of the household at all times of the day, regardless of whether or not a building may be occupied. If a building is not occupied during the time that the thermostat set backs are in place any uncomfortable indoor environmental conditions that may results will not affect occupants until the building is occupied. However, additional information and evaluation is needed to further investigate and quantify these potential differences and influences.

Finally, while this research focuses on assessing the potential energy savings achieved through reduced HVAC use and compares this to the thermal comfort indices, it does not discuss how this translates to cost savings to the consumer. Depending on the pricing strategy of electricity utilized, including both the off-peak and on-peak electricity costs, and the relative difference between the two, the energy savings achieved may translate to a range of cost savings to the residential consumer. The range in energy prices in the U.S. varies by more than $20 \mathrm{cent} / \mathrm{kWh}$. Similarly, there is a significant range in the possible price difference between on-peak and offpeak pricing. The pricing of electricity may also affect occupant behavior. An in-depth economic 
analysis is needed to assess these variations in costs and such an analysis is considered a subject for future work.

Acknowledging the discussed limitations, this research provides information that is valuable in evaluating the effects of TOU pricing on thermal comfort for different climate zones, and homes with different characteristics, and compares these effects to energy use. In addition it expands upon the use of the RSM methodology beyond previously research.

\section{Conclusions}

One of the main purposes of time-of-use pricing is to encourage changes in building operations to reduce peak load on the electric grid. This study focuses on residential buildings with smart thermostats that can automatically set back the thermostat of the HVAC during the on-peak period. This reduces demand on the electric grid and also reduces energy use. The following conclusions can be drawn from this study.

1) A second-order response surface provides a good fit to in-sample and out-of-sample data in predicting the Average PPD for a residential building energy model using a $3^{\mathrm{n}}$ full factorial design. This is consistent across all climate zones studied. For the percent of time outside the thermal comfort zone (POS), the second-order response surface provides a good fit to insample data, and slightly under-predicts out-of-sample values.

2) The strongest influencing factor on the long-term thermal comfort indices studied is the indoor set point temperature, of the four studied design variables (thermal mass, setback temperature, set point temperature, and air exchange rate). Air exchange rate and thermal mass are less influential on thermal comfort. Increasing the set point temperature by one degree increases the Average PPD by 2 to $7 \%$, and POS by 8 to $17 \%$. 
3) An increase in the degrees of setback temperature generally decreases the thermal comfort of occupants. This influence is greatest in the hot-dry climate zone (2b) of the three climate zones studied. Compared to a constant set point temperature in which the temperature is constant even during on-peak times, the Average PPD increases 2\%-4.5\%, and the POS increases $5 \%-10 \%$.

4) Probabilistic analysis demonstrates, based on the distributions of design variables of new, single family residential buildings, that the mixed climate zone will maintain a threshold $10 \%$ Average PPD more easily than the hot climate zones in the implementation of TOU pricing.

5) Regarding HVAC use, the set point temperature is an important influencing factor in all climate zones. A one degree increase in set point temperature decreases the HVAC energy use by $300-400 \mathrm{kWh}(24-31 \%), 400-600 \mathrm{kWh}(17-19 \%)$, and 500-600 kWh (9-10\%) in climate zones $4 \mathrm{a}, 3 \mathrm{a}$ and $2 \mathrm{~b}$ respectively. The decrease in HVAC energy use achieves the greatest energy savings in the hot-dry climate zone, but the largest percent savings in the mixed-humid climate zone.

6) HVAC use is negatively correlated with the Average PPD and POS, meaning a decrease in HVAC use increases the Average PPD and POS, negatively affecting occupants. In general the HVAC energy use decreases 100-130 kWh for each degree of increase in Average PPD, and 21 to $30 \mathrm{kWh}$ decrease for each additional percent outside the thermal comfort zone (POS). This decrease in energy use per POS and Average PPD is highest in the hot-dry climate (2b) as compared to the other studied climates.

7) In choosing which thermal comfort index is appropriate for use in evaluating long term thermal comfort of the two studied, the Average PPD can capture a wider range of thermal discomfort as compared to the POS. POS also does not measure severity of the discomfort. 
Over an equivalent level of Average PPD of $26 \%$, the POS is at $100 \%$, after which any

additional changes to the indoor environment will not be captured by this POS index.

The results of this research are helpful in understanding the influencing factors on occupant comfort for buildings operating under time-of-use pricing, and their relationship to HVAC use. This type of analysis could be used by utility companies to determine what the potential savings would be achieved in implementing smart thermostat-enabled time of use pricing schedule, and the anticipated effect on thermal comfort.

\section{Acknowledgements:}

This work was supported by the National Science Foundation IGERT Grant no. DGE-0966298.

Any opinion, findings, and conclusions or recommendations expressed in this material are those of the authors and do not necessarily reflect the views of the National Science Foundation.

\section{References}

[1] Klepeis NE, Nelson WC, Ott WR, Robinson JP, Tsang AM, Switzer P, Engelmann WH. The National Human Activity Pattern Survey (NHAPS): a resource for assessing exposure to environmental pollutants. Journal of exposure analysis and environmental epidemiology; 2001;11(3):231-252.

[2] Schellen L, van Marken Lichtenbelt WD, Loomans MGLC, Toftum J, De Wit MH. Differences between young adults and elderly in thermal comfort, productivity, and thermal physiology in response to a moderate temperature drift and a steady-state condition. Indoor air 2010;20(4):273-283.

[3] Akimoto T, Tanabe SI, Yanai T, Sasaki M. Thermal comfort and productivity-Evaluation of workplace environment in a task conditioned office. Building and Environment, 2010;45(1):4550 .

[4] United States Energy Information Administration. RECS, Residential Energy Consumption Survey, 2009. U.S. Department of Energy, Washington D.C., U.S.A.

[5] Electric Reliability Council of Texas (ERCOT). Hourly Load Data Archives: 2014 ERCOT Hourly Load Data. http://www.ercot.com/gridinfo/load/load_hist/

[6] ASHRAE. ANSI/ASHRAE/IES Standard 90.1-2013: Energy Standard for Buildings Excet Low-Rise Residential Buildings. 2013.

[7] Wattles P. Demand Response and ERCOT Grid Reliability. Energy Efficiency Forum Arlington, TX May 23, 2012.

[8] Newsham GR, Bowker BG. The effect of utility time-varying pricing and load control strategies on residential summer peak electricity use: a review. Energy policy 2010;38(7):32893296. 
[9] Cetin KS, Tabares-Velasco PC, Novoselac A. Appliance daily energy use in new residential buildings: Use profiles and variation in time-of-use. Energy and Buildings 2014;84:716-726.

[10]ASHRAE. Standard 55-2013 - Thermal Environmental Conditions for Human Occupancy. 2013.

[11] Fanger PO. Calculation of thermal comfort, Introduction of a basic comfort equation. ASHRAE transactions, 1967;73(2):III-4.

[12] Fanger PO. Thermal comfort: McGraw Hill: New York; 1972.

[13] International Standards Organization. ISO 7730 - Ergonomics of the thermal environment Analytical determination and interpretation of thermal comfort using calculation of the PMV and PPD indices and local thermal comfort criteria, International Organization for Standardization, Switzerland, 2005.

[14] EN 15251. Indoor environmental input parameters for design and assessment of energy performance of buildings-addressing indoor air quality, thermal environment, lighting and acoustics. 2006.

[15] Carlucci S, Attia S. Impact of different thermal comfort models on zero energy residential buildings in hot climates. Energy and Buildings 2015; 102:117-128.

[16] Carlucci S, Pagliano L. A review of indices for the long-term evaluation of the general thermal comfort conditions in buildings. Energy and Buildings, 2012;53:194-205.

[17] Hensen JL, Lamberts R. Building performance simulation for design and operation. Spon Press: New York; 2012

[18] Olesen BW, Brager GS. A better way to predict comfort: The new ASHRAE standard 552004. ASHRAE Journal; 8:20-26.

[19] Cetin KS, Manuel L, Novoselac A. Thermal Comfort Evaluation for Mechanically Conditioned Buildings using Response Surfaces in an Uncertainty Analysis Framework. Science and Technology for the Built Environment. In Press 2015.

[20] Borgeson S, Brager GS. Comfort exceedance metrics in mixed-mode buildings. Proceedings of Conference: Adapting to Change: New Thinking on Comfort Cumberland Lodge, Windsor. 2010 .

[21] Nicol JF, Hacker J, Spires B, Davies H. Suggestion for new approach to overheating diagnostic. Proceedings of Air Conditioning and the Low Carbon Cooling Challenge, Cumberland Lodge, Windsor, UK; 27-29 July 2008.

[22] Sage-Lauck JS, Sailor DJ. Evaluation of phase change materials for improving thermal comfort in a super-insulated residential building. Energy and Buildings, 2014;79:32-40.

[23] Box GE, Wilson KB. On the experimental attainment of optimum conditions. Journal of the Royal Statistical Society. Series B, 1951;13(1):1-45.

[24] Khalajzadeh V, Heidarinejad G, Srebric J. Parameters optimization of a vertical ground heat exchanger based on response surface methodology. Energy and Buildings, 2011;43(6): 12881294.

[25] Kang SC., Koh HM, Choo JF. An efficient response surface method using moving least squares approximation for structural reliability analysis. Probabilistic Engineering Mechanics, 2010;25(4):365-371.

[26] Eisenhower B, O'Neill Z, Fonoberov VA, Mezić I. Uncertainty and sensitivity decomposition of building energy models. Journal of Building Performance Simulation, 2012;5(3):171-184.

[27] Goyal S, Barooah P. A method for model-reduction of non-linear thermal dynamics of multi-zone buildings. Energy and Buildings, 2012;47:332-340. 
[28] Cole WJ, Hale ET, Edgar TF. Building energy model reduction for model predictive control using OpenStudio. IEEE American Control Conference 2013;449-454.

[29] Yuce B, Li H, Rezgui Y, Petri I, Jayan B, Yang C. Utilizing artificial neural network to predict energy consumption and thermal comfort level: An indoor swimming pool case study. Energy and Buildings, 2014;80:45-56.

[30] Chang YC, Lu JT, Liu YC, Wang CH. Using Artificial Neural Network to Execute Demand Response Considering Indoor Thermal Comfort and Forecast Load-Shedding. Applied Mechanics and Materials 2015;716:1399-1408.

[31] Ashtiani A, Mirzaei PA, Haghighat F. Indoor thermal condition in urban heat island: Comparison of the artificial neural network and regression methods prediction. Energy and Buildings, 2014;76:597-604.

[32] Wilcox, S. (2007). National Solar Radiation Database 1991-2005 Update: User's Manual (No. NREL/TP-581-41364). National Renewable Energy Laboratory (NREL), Golden, CO. http://rredc.nrel.gov/solar/old_data/nsrdb/1991-2005/tmy3/

[33] International Code Council. International Energy Conservation Code. 2009.

[34] Hendron R, Engebrecht C. Building America House Simulation Protocol, National Renewable Energy Lab, 2010.

[35] Fang X, Winkler J, Christensen D. 2011. Using EnergyPlus to Perform Dehumidification Analysis on Building American Homes. NREL/JA-5500-49899

[36] Woods J, Winkler J, Christensen D 2013. Moisture Modeling: Effectives Moisture Penetration Depth Versus Effective Capacitance. Thermal Performance of the Exterior Envelopes of Whole Buildings XII International Conference

[37] Air Conditioning Contractors of America. Residential Load Calculations: Manuel J. 2011.

[38] Keeney KR, Braun JE. A simplified method for determining optimal cooling control strategies for thermal storage in building mass. International Journal of HVAC\&R Research 1996;2(1):1-20.

[39] Keeney KR, Braun JE. Application of building precooling to reduce peak cooling requirements. ASHRAE Transactions 1997; 103(1):463-469.

[40] Henze GP, Kalz D, Liu S, Felsmann C. Experimental Analysis of Model-Based Predictive Optimal Control for Active and Passive Building Thermal Storage Inventory." International Journal of HVAC\&R Research, 2005;11(2):189-214.

[41] Henze GP, Felsmann C, Florita AR, Brandemuehl MJ, Cheng H, Waters CE. Optimization of Building Thermal Mass Control in the Presence of Energy and Demand Charges (1313-RP). ASHRAE Transactions, 2008;114(2): 75:84.

[42] Siemann M. Performance and Application of Residential Building Energy Grey-Box Models. Dissertation. University of Maryland. 2013.

[43] Offermann FJ. Ventilation and Indoor Air Quality in New Homes. Califorina Energy Commission PIER Collaboration Report. 2009.

[44] Pecan Street Research Institute. Dataport: residential building energy consumption database. https://dataport.pecanstreet.org/

[45] U.S. Department of Energy. EnergyPlus Version 8.2 Energy Simulation Software. http://apps1.eere.energy.gov/buildings/energyplus/

[46] Meyer RH, Montgomery DC, Anderson-Cook CM. 2011. Response Surface Methodology: Process and Product Optimization Using Designed Experiments

[47] Khuri AI, Mukhopadhyay S. Response surface methodology.Wiley Interdisciplinary Reviews: Computational Statistics, 2010;2(2):128-149. 
[48] Hammersley JM, Handscomb DC. Percolation processes. Monte Carlo Methods Springer Netherlands. 1964:134-141.

[49] Balaras CA. The role of thermal mass on the cooling load of buildings. An overview of computational methods. Energy and Buildings. 1996:24(1), 1-10.

[50] La Roche P, Milne M. Effects of window size and thermal mass on building comfort using an intelligent ventilation controller. Solar Energy. 2004;77(4):421-434.

[51] Ogoli DM. Predicting indoor temperatures in closed buildings with high thermal mass. Energy and Buildings, 2003;35(9):851-862.

[52] Berardi BM, Leonie E, Marchesini B, Cascella D, Raffi GB. Indoor climate and air quality in new offices: effects of a reduced air-exchange rate. International archives of occupational and environmental health, 1991:63(4);233-239.

[53] Rijal HB, Tuohy P, Humphreys MA, Nicol JF, Samuel A, Clarke J. Using results from field surveys to predict the effect of open windows on thermal comfort and energy use in buildings. Energy and buildings,2007:39(7);823-836.

[54] Isaac M, Van Vuuren DP. Modeling global residential sector energy demand for heating and air conditioning in the context of climate change. Energy Policy, 2009:37(2);507-521.

[55] Cetin KS, Novoselac A. Single and multi-family residential central all-air HVAC system operational characteristics in cooling-dominated climate. Energy and Buildings, 2015;96:210220.

[56] Zhang H, Huizenga C, Arens EA, Yu T. Modeling thermal comfort in stratified environments. Proceedings from Indoor Air 2005. Beijing, China. 133-137.

[57] Wyon DP, Sandberg M. Vertical temperature gradients, mean room temperatures and their effects on thermal discomfort. National Swedish Institute for Building Research. 1993. [58] Olesen BW, Scholer M, Fanger PO. Discomfort caused by vertical air temperature differences," Indoor Climate, Danish Building Institute, Copenhagen 1979.

[59] Rhodes JD, Stephens B, Webber ME. Energy audit analysis of residential air-conditioning systems in Austin, Texas. ASHRAE Transactions, 2012;118(1):143-150

[60] Henze G, Pfafferott J, Herkel S, Felsmann C. Impact of adaptive comfort criteria and heat waves on optimal building thermal mass control. Energy and Buildings. 2007; 29:221-235

[61] Peeters L, De Dear R, Hensen J, D'haeseleer W. Thermal comfort in residential buildings: Comfort values and scales for building energy simulation. Applied Energy, 2009;86(5), 772-780. [62] Wong LT, Mui KW, Cheung CT. Bayesian thermal comfort model. Building and Environment, 2014;82:171-179. 